\title{
Genetic Interactions of Yeast Eukaryotic Translation Initiation Factor 5A (eIF5A) Reveal Connections to Poly(A)-Binding Protein and Protein Kinase C Signaling
}

\author{
Sandro R. Valentini, ${ }^{*, \dagger}$ Jason M. Casolari,* Carla C. Oliveira, ${ }^{\ddagger}$ Pamela A. Silver, ${ }^{*, 1}$ \\ and Anne E. McBride*,2 \\ *Department of Biological Chemistry and Molecular Pharmacology, Harvard Medical School, and Department of Cancer Biology, \\ Dana-Farber Cancer Institute, Boston, Massachusetts 02115, ${ }^{\dagger}$ Department of Biological Sciences, School of Pharmacy, \\ São Paulo State University, Araraquara, SP, 14801-902, Brazil and $\ddagger^{\ddagger}$ Department of Biochemistry, Institute of \\ Chemistry, University of São Paulo, São Paulo, SP 05508-900, Brazil \\ Manuscript received April 25, 2001 \\ Accepted for publication October 30, 2001
}

\begin{abstract}
The highly conserved eukaryotic translation initiation factor eIF5A has been proposed to have various roles in the cell, from translation to mRNA decay to nuclear protein export. To further our understanding of this essential protein, three temperature-sensitive alleles of the yeast TIF51A gene have been characterized. Two mutant eIF5A proteins contain mutations in a proline residue at the junction between the two eIF5A domains and the third, strongest allele encodes a protein with a single mutation in each domain, both of which are required for the growth defect. The stronger tif5 $1 A$ alleles cause defects in degradation of short-lived mRNAs, supporting a role for this protein in mRNA decay. A multicopy suppressor screen revealed six genes, the overexpression of which allows growth of a tif51A-1 strain at high temperature; these genes include PAB1, PKC1, and PKC1 regulators WSC1, WSC2, and WSC3. Further results suggest that eIF5A may also be involved in ribosomal synthesis and the WSC/PKC1 signaling pathway for cell wall integrity or related processes.
\end{abstract}

$\mathrm{R}^{\mathrm{E}}$ EGULATION of the fate of cytoplasmic mRNA involves a delicate balance between its recruitment to ribosomes for translation and its degradation by nucleolytic enzymes. As researchers have studied separately the factors that are important for translation and those that are required for mRNA turnover, it has become clear that these two processes are intimately linked. eIF5A is an enigmatic protein that has been implicated in several steps of RNA metabolism including both translation and mRNA degradation.

eIF5A is a highly conserved protein encoded in the genomes of eukaryotes and archaebacteria (CHEN and LiU 1997). Yeast and mammalian eIF5A proteins are $63 \%$ identical, suggesting the importance of this protein in basic cellular processes (SCHNIER et al. 1991). Originally purified from ribosomes of rabbit reticulocyte lysates (Kemper et al. 1976), eIF5A was described as a translation initiation factor due to its ability to stimulate the synthesis of methionyl-puromycin in vitro (BENNE and Hershey 1978; Park et al. 1993). However, depletion of this factor in yeast caused only a small $(30 \%)$ reduction in the protein synthesis rate (KANG and HeRSHEY 1994). These results have been used to argue against

${ }^{1}$ Corresponding author: Dana-Farber Cancer Institute, 44 Binney St., SM922, Boston, MA 02115. E-mail: pamela_silver@dfci.harvard.edu

${ }^{2}$ Present address: Department of Biology, Bowdoin College, Brunswick, ME 04011.
eIF5A being an initiation factor for general protein synthesis.

Alternatively, it was suggested that eIF5A could be involved in the translation of a specific subset of mRNAs, for example, those involved in the cell cycle progression (G1/S transition; PARK et al. 1993, 1997). Expression of eIF5A has also been correlated with cell proliferation: an increase in G1-arrested cells is observed after depletion of this factor in yeast (KANG and Hershey 1994). Conversely, eIF5A expression is induced in activated human T lymphocytes (Bevec et al. 1994).

The yeast Saccharomyces cerevisiae contains two $90 \%$ identical genes encoding eIF5A, TIF51A (HYP2), and TIF51B (HYP1) (SCHNIER et al. 1991), and each of these proteins undergoes two post-translational modifications. The N-terminal acetylated serine residue of eIF5A is phosphorylated (KANG et al. 1993; KuIER et al. 1993), and mutational analysis revealed that unphosphorylated eIF5A is sufficient to support growth of a tif5 1A $A$ haploid strain (KLIER et al. 1993), demonstrating that phosphorylation is not essential for eIF5A function in vivo. The second modification is hypusination of a specific lysine (CHEN and LiU 1997; PARK et al. 1997). Hypusination of eIF5A is essential in yeast: strains in which hypusination is blocked, by mutation of the target lysine (K51R) or deletion of the deoxyhypusine synthase gene, are inviable (Schnier et al. 1991; Sasaki et al. 1996; Park et al. 1998). Similarly, inhibitors of hypusination block the proliferation of different mammalian cell lines (HAN- 
TABLE 1

Yeast strains used in this study

\begin{tabular}{|c|c|c|}
\hline Strain & Genotype & Source \\
\hline W303a & MATa ade2-1 trp1-1 ura3-1 leu2-3,112 his3-11,15 can1-100 & A. Tzagoloff \\
\hline $\mathrm{W} 303 \alpha$ & 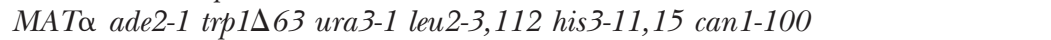 & A. Tzagoloff \\
\hline FY23 & MATa $\operatorname{ura3}-52 \operatorname{trp} 1 \Delta 63$ leu $2 \Delta 1$ & F. Winston \\
\hline DL376 & 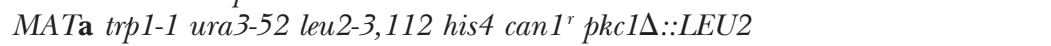 & D. Levin \\
\hline xpo1-1 & $\begin{array}{l}\text { MATa ade2-1 trp1-1 ura3-1 leu2-3,112 his3-11,15 can1-100 xpo1::LEU2 + } \\
\quad \text { pKW457 (xpo1-1 HIS3) }\end{array}$ & $\mathrm{K}$. Weis \\
\hline PSY8 & MATa ade2-1 trp1-1 ura3-1 leu2-3,112 his3-11,15 can1-100 cyt1::HIS3 tif51A-1 & A. Chiang \\
\hline PSY338 & 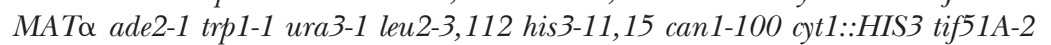 & A. Chiang \\
\hline PSY341 & MATa ade2-1 trp1-1 ura3-1 leu2-3,112 his3-11,15 can1-100 cyt1::HIS3 tif51A-3 & A. Chiang \\
\hline PSY1241 & MATa ade2-1 trp1-1 leu2-3,112 his3-11 can1-100 TIF51A::URA3 & This study \\
\hline PSY1242 & MAT $\alpha$ ade2-1 trp1-1 ura3-1 his3-11,15 leu2-3,112 can1-100 cyt1::HIS3 tif51A-1 & This study \\
\hline PSY1243 & 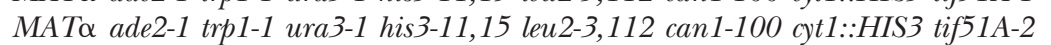 & This study \\
\hline PSY1244 & 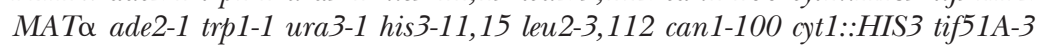 & This study \\
\hline PSY1245 & 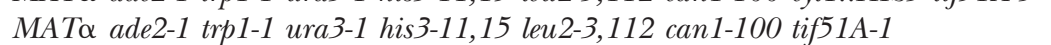 & This study \\
\hline PSY1248 & MATa ade2-1 trp1-1 ura3-1 his3-11,15 leu2-3,112 can1-100 tif51A-2 & This study \\
\hline PSY1249 & MATa ade2-1 trp1-1 ura3-1 his3-11,15 leu2-3,112 can1-100 tif51A-3 & This study \\
\hline PSY1250 & $M A T \mathbf{a} / \alpha$ ura3-52/- leu2s $1 /-$ his $3 \Delta 200 /-\operatorname{trp} 1 \Delta 63 /+$ & This study \\
\hline PSY1251 & 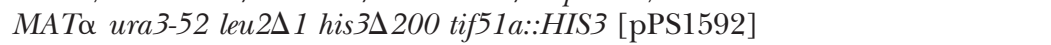 & This study \\
\hline PSY1252 & MATa ade2-1 trp1-1 ura3-1 his3-11,15 leu2-3,112 can1-100 cyt1::HIS3 tif51A-1 & This study \\
\hline
\end{tabular}

AUSKe-Abel et al. 1994; PARK et al. 1994; CHEN et al. 1996; SHI et al. 1996a). eIF5A is the only eukaryotic protein known to be hypusinated.

Although eIF5A has been suggested to participate in the nucleocytoplasmic trafficking of the HIV-1 Rev protein/RRE complex (RUHL et al. 1993; BEvEc et al. 1996; Bevec and Hauber 1997; Liu et al. 1997; Hofmann et al. 2001), other studies do not agree on such a role for eIF5A (Henderson and Percipalle 1997; Shi et al. 1997; LIPOWsky et al. 2000). Localization studies also do not support the involvement of this protein in the nuclear transport of macromolecules. In mammalian cells, eIF5A is mainly cytoplasmic with a fraction associated with the endoplasmic reticulum (ER) membrane through ribosomes (SHI et al. 1996b). Its cytoplasmic localization, combined with its interaction with the ribosomal protein L5 (ScHATz et al. 1998), strengthens the connection between eIF5A and translation.

Recently it was shown that a yeast mutant harboring a temperature-sensitive allele of TIF51A exhibits a defect in mRNA decay, accumulating uncapped mRNAs at the restrictive temperature. In addition, this strain shows an $\sim 30 \%$ decrease in protein synthesis at high temperature (Zuk and JAcobson 1998). These results suggest that eIF5A may be involved in mRNA degradation as well as translation.

Here we have characterized three novel alleles of TIF51A and have used them to address the proposed functions of eIF5A. We also present data linking eIF5A with both poly(A)-binding protein and protein kinase C. The isolation of $P A B 1$ and PKC1 as multicopy suppressors of a temperature-sensitive allele of TIF51A, tif51A-1, suggests important connections between these three proteins and their roles in RNA metabolism, including translation, mRNA decay, and ribosome biogenesis.

\section{MATERIALS AND METHODS}

Yeast strains, growth conditions, and plasmids: S. cerevisiae strains and their genotypes used in this work are listed in Table 1. Procedures for cell growth and genetic manipulations were according to standard protocols (Rose et al. 1990). Plasmids used in this work were obtained as described below and are listed in Table 2. Cloning by PCR was performed with Pfu DNA polymerase (Stratagene, La Jolla, CA) or Vent DNA polymerase (New England Biolabs, Beverly, MA) and oligonucleotides listed in Table 3 .

Construction of a marked TIF51A allele and linkage assays: To mark TIF51A with the URA3 gene, a 1.4-kb PstI fragment containing TIF51A was removed from the plasmid pPS1483 and ligated into the NsiI site of the vector YIp5, generating the plasmid pPS1591. This plasmid was linearized using HpaI, which cleaves within the TIF51A gene, and used to transform a W303a/ $\alpha$ diploid strain. After selection on uracil dropout plates, transformed diploids were sporulated. Genomic DNA from the selected diploids and their haploid progeny was digested with $P s t \mathrm{I}$ and subjected to Southern blot analysis using the 1.4-kb PstI fragment as a probe. One of the haploid cells that contained the URA3 gene integrated next to TIF51A was chosen for linkage assay (PSY1241). To examine linkage of the tif5 $1 \mathrm{~A}$ temperature-sensitive (ts) alleles and TIF51A, the tif51A mutants (PSY1242-PSY1244) were initially crossed to this strain containing a TIF51A-marked allele (PSY1241). The diploids resulting from these crosses were sporulated and subjected to tetrad analysis.

Amplification and sequencing of the tif51A temperaturesensitive alleles: Genomic DNA was prepared from the tif $51 \mathrm{~A}$ temperature-sensitive strains (PSY1245, PSY1248, and PSY1249). The TIF51A gene was amplified by PCR using Taq DNA polymerase (Perkin-Elmer, Norwalk, CT) and the primers NPL2-A and NPL2-B. PCR products were purified and se- 
TABLE 2

Plasmids used in this study

\begin{tabular}{|c|c|c|}
\hline Plasmid & Features & Source \\
\hline pGEX-4T-1 & Bacterial expression vector for GST fusion proteins & Pharmacia \\
\hline pRS315 & Yeast LEU2 CEN expression vector & Sikorski and Hieter (1989) \\
\hline pRS316 & Yeast URA3 CEN expression vector & Sikorski and Hieter (1989) \\
\hline pRS426 & Yeast URA3 $2 \mu$ expression vector & Christianson et al. (1992) \\
\hline pPS1483 & 1.4-kb PstI fragment with TIF51A in YCpLacIII LEU2 CEN & R. Zitomer \\
\hline pPS1494 & Yeast Gal GFP-Rev URA3 $2 \mu$ & TAURA et al. (1998) \\
\hline YIp5 & URA3 targeted integration vector & STRUHL et al. (1979) \\
\hline pCGF-1a & Yeast Gal GFP URA3 $2 \mu$ expression vector & KAHANA and Silver (1996) \\
\hline pPS1591 & TIF5 1A PstI fragment in YIp5 & This study \\
\hline pPS1592 & TIF51A in pRS316 & This study \\
\hline pPS1593 & tif5 $1 A-1$ in pRS315 & This study \\
\hline pPS1594 & tif5 $1 A-2$ in $\mathrm{pRS} 315$ & This study \\
\hline pPS1595 & tif5 $1 A-3$ in pRS315 & This study \\
\hline pPS1596 & TIF5 $1 A$ in pGEX-4T-1 & This study \\
\hline pPS1597 & TIF5 $1 A$ in pCGF-1a & This study \\
\hline pPS1598 & TIF5 $1 A$ in pRS426 & This study \\
\hline pPS1599 & YOR $137 C$ in pRS426 & This study \\
\hline pPS1600 & FspI-NotI fragment containing PKC1 in pRS426 & This study \\
\hline pPS1601 & $P A B 1$ in $\mathrm{pRS} 426$ & This study \\
\hline pPS1602 & WSC1 in pRS426 & This study \\
\hline pPS1603 & WSC2 in pRS426 & This study \\
\hline pPS1604 & WSC 3 in pRS426 & This study \\
\hline pPS2440 & $P K C 1:: H A$ in $\mathrm{pPS} 1600$ & This study \\
\hline pPS2441 & $p k c 1-K 853 R:: H A$ in pPS1600 & This study \\
\hline
\end{tabular}

quenced using the same primers at the Dana-Farber Cancer Institute Molecular Biology Core Facility.

Cloning TIF51A and the tif51A temperature-sensitive alleles: TIF5 $1 A$ was cloned from genomic DNA purified from a wildtype strain (FY23) and the ts alleles from the tif51A ts strains (PSY1245, PSY1248, and PSY1249). PCR reactions were performed using primers NPL2-C and NPL2-D, which contain a BamHI site. PCR products were digested with BamHI and gel purified. The fragment containing wild-type TIF51A was cloned into the BamHI site of pRS316, generating the plasmid pPS1592. For the mutated alleles, PCR fragments were transferred into pRS315, resulting in plasmids pPS1593 (tif51A-1), pPS1594 (tif51A-2), and pPS1595 (tif51A-3). All constructs were confirmed by sequencing.

Disruption of TIF51A: A PCR strategy (BAUDIN et al. 1993) was used to disrupt TIF51A in a wild-type diploid (PSY1250). Briefly, a DNA fragment containing the HIS3 gene flanked by the $5^{\prime}$ and $3^{\prime}$ sequences of TIF51A was obtained by PCR using primers NPL2-G and NPL2-H. The PCR product was purified and transformed into PSY1250. Transformants were selected on histidine dropout plates and screened by PCR. A diploid strain harboring a disrupted copy of TIF51A was selected, transformed with pPS1592, sporulated, and subjected to tetrad analysis. The tif51A::HIS3 disruption was confirmed by PCR and Southern blot. One strain carrying the tif5 1A::HIS3 disruption (PSY1251) was chosen to confirm the function of the plasmid-borne mutated alleles.

Anti-eIF5A Western blotting: To produce anti-eIF5A antisera, a plasmid to express GST-eIF5A in Escherichia coli (pPS1596) was constructed as follows. The TIF51A gene was amplified by PCR from genomic DNA of a wild-type strain (FY23) using primers TIF51A-1 and TIF51A-2. The PCR product was digested with $B a m \mathrm{HI}$ and $A v a \mathrm{I}$, gel purified, and ligated into pGEX-4T-1 (Pharmacia, Piscataway, NJ) that had been digested with BamHI and SaII. GST-eIF5A was bacterially expressed from this plasmid, the fusion protein purified, and eIF5A released from GST-eIF5A by thrombin (Sigma, St. Louis) cleavage essentially as described (Henry and Silver 1996). A polyclonal anti-eIF5A rabbit antiserum was raised at Covance Research Products using this recombinant eIF5A as immunogen.

To determine eIF5A levels in tif51A mutant strains, cells were grown to midlog phase at $25^{\circ}$, shifted to $37^{\circ}$ or left at $25^{\circ}$ for $3 \mathrm{hr}$, and then lysed in radio-immune precipitation buffer $(150 \mathrm{~mm} \mathrm{NaCl}, 1 \%$ Nonidet P-40, $0.5 \%$ deoxycholate, $0.1 \%$ SDS, $50 \mathrm{~mm}$ Tris-HCl, $\mathrm{pH} 8.0$ ) with $1 \mathrm{~mm}$ phenylmethylsulfonyl fluoride as previously described (MCBRIDE et al. 2000). Total protein $(5 \mu \mathrm{g})$ was resolved by SDS-PAGE, transferred to nitrocellulose, and eIF5A levels were detected by immunoblotting with a 1:10,000 dilution of anti-eIF5A antiserum and enhanced chemiluminescence detection (Amersham, Buckinghamshire, UK).

Localization of eIF5A: Indirect immunofluorescence was used to localize endogenous eIF5A using the polyclonal antieIF5A at a dilution of 1:1000. This experiment was performed essentially as described (LEE et al. 1996). Localization of eIF5A in wild-type (FY23) and xpo1-1 (STADE et al. 1997) cells was determined following a 1-hr shift to $37^{\circ}$.

To localize eIF5A in living cells, a plasmid that expressed a fusion between green fluorescent protein (GFP) and eIF5A was transformed into a wild-type strain (FY23). This plasmid, pPS1597, was generated by PCR amplification of TIF51A from FY23 genomic DNA using primers NPL2-L and NPL2-M. The PCR product was digested with BamHI and HindIII and ligated into the pCGF-1a vector (KAHANA and Silver 1996), placing GFP-TIF51A under the control of a galactose-inducible promoter. GFP fusion proteins were visualized after $1-3 \mathrm{hr}$ of induction as described (LeE et al. 1996). 
TABLE 3

Oligonucleotides used in this study

\begin{tabular}{|c|c|c|}
\hline Oligo & Sequence $\left(5^{\prime}-3^{\prime}\right)^{a}$ & Site \\
\hline NPL2-A & GCCAATTACTCATAGACTCC & \\
\hline NPL2-B & GCGAAGAGTACATGATGTGA & \\
\hline NPL2-C & CGCGGATCCTGTATTCCGTAGCGTTATATCG & BamHI \\
\hline NPL2-D & 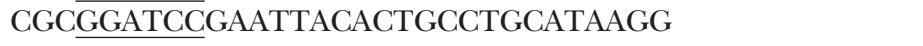 & BamHI \\
\hline NPL2-G & $\begin{array}{l}\text { АCTCATAGACTCCCAAACACACACAAATACCAACTCATATATACA } \\
\text { GGCCTCCTCTAGTACACTC }\end{array}$ & \\
\hline NPL2-H & $\begin{array}{l}\text { TTTTTTCTTTTTTCATTTATATCCCATGCCATGATGTTAACCGGT } \\
\text { GCGCGCCTCGTTCAGAATG }\end{array}$ & \\
\hline NPL2-L & CGCGGATCCATGTCTGACGAAGAACATACG & BamHI \\
\hline NPL2-M & CCCAAGCTTAGCCGGTAGATATGCGC & HindIII \\
\hline TIF51A-1 & $\begin{array}{l}\text { CGCGGATCCATGTCTGACGAAGAACATACCCCGCTCGAG } \\
\text { CCGGTAGATATGCGC }\end{array}$ & $\begin{array}{l}\text { BamHI TIF51A-2 } \\
\text { XhoI/AvaI }\end{array}$ \\
\hline $137-\mathrm{E}$ & CGCGGATCCCGGACATAAATTAGACTCTAAGG & BamHI \\
\hline $137-\mathrm{F}$ & CGCGGATCCGTATCTACTCCAAACTTCTATGG & BamHI \\
\hline PAB1-C & CGCGGATCCAAGAGGTCATACTGTATGAAGCC & BamHI \\
\hline PAB1-D & CGCGGATCCAGTATTTTCCTGGAACCTGTTGG & BamHI \\
\hline WSC1-A & 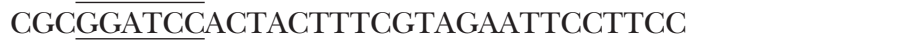 & BamHI \\
\hline WSC1-B & CGCEGATCCCTATGTAACTAAGTTAAGGTTGG & BamHI \\
\hline WSC2-A & CGCGGATCCATCTAGCACTTCTCCCAGAAGTGC & BamHI \\
\hline WSC2-B & CGCGGATCCTGATGGTGATTTGAGACAGACC & BamHI \\
\hline WSC3-A & CGCGGATCCAGCCGATTCGTTAGTAGGAATGC & BamHI \\
\hline WSC3-B & CGCGGATCCGTACCACAAACATCATTAGAAGCTGC & BamHI \\
\hline
\end{tabular}

${ }^{a}$ Introduced restriction sites are underlined and italics indicate TIF51A sequences.

mRNA stability assay: Exponentially growing yeast cultures were shifted from $25^{\circ}$ to $37^{\circ}$. At various times, samples were collected and quickly frozen in a dry ice-ethanol bath. Total RNA was isolated from yeast cells by a modified hot phenol method (OliveIra and McCARTHY 1995). Yeast strains were incubated for $4 \mathrm{hr}$ at $37^{\circ}$, when $20 \mu \mathrm{g} / \mathrm{ml}$ thiolutin was added and samples were taken at $0,5,10,15,20$, and $30 \mathrm{~min}$ after addition of thiolutin. RNAs were separated by electrophoresis on $1.3 \%$ agarose gels, after denaturing with glyoxal. RNA gels were subjected to Northern blotting using Hybond nylon membranes (Amersham). Membranes were probed with a ${ }^{32}$ P-labeled oligonucleotide complementary to the $25 \mathrm{~S}$ rRNA and a random primer-labeled DNA fragment corresponding to the HHT2 gene. Blots were analyzed by using a phosphorimager (Molecular Dynamics, Sunnyvale, CA).

High-copy suppressor screen: A URA $3 / 2 \mu$ genomic yeast library (ConNELLY and Hieter 1996) was transformed into a tif51A-1 strain (PSY1252). Approximately 140,000 transformants were selected by plating on uracil dropout plates, incubating at $25^{\circ}$ overnight, and shifting plates to $36^{\circ}$ for $3-4$ days. Plasmids were rescued from temperature-resistant clones and retransformed into PSY1252 to show plasmid linkage. The genomic segment present in each of the selected clones was determined by sequencing the ends with $\mathrm{T} 3$ and $\mathrm{T} 7$ primers and using these sequences to search the $S$. cerevisiae genome database.

High-copy suppressor genes were characterized by subcloning different segments of the original clone into pRS426 $(U R A 3 / 2 \mu)$ and testing in PSY1252. The minimal suppressing subclone containing the $P K C 1$ open reading frame (ORF) is pPS1600. Also, TIF51A and the five other high-copy suppressor genes were cloned into pRS426 using the following primers containing a BamHI site: NPL2-C and NPL2-D to clone TIF51A (pPS1598); 137-E and 137-F to clone YOR137C (pPS1599); PAB1-C and PAB1-D to clone PAB1 (pPS1601); WSC1-A and WSC1-B to clone WSC1 (pPS1602); WSC2-A and WSC2-B to clone WSC2 (pPS1603); and WSC3-A and WSC3-B to clone WSC3 (pPS1604). In addition, hemagglutinin (HA)-tagged forms of wild-type and K853R mutant PKC1 were subcloned into pPS1600 by digestion of pGAL[PKC1::HA] and pGAL[pkc1K853R::HA] (WATANABE et al. 1994) with MscI and SphI and insertion of the 2.4-kb fragment into $M s c \mathrm{I} / S p h \mathrm{I}$-digested pPS1600, resulting in pPS2440 and pPS2441, respectively.

\section{RESULTS}

Characterization of three new temperature-sensitive alleles of TIF51A: In a screen for conditional mutants defective in nuclear protein localization in the yeast $S$. cerevisiae, several complementation groups were obtained (SADLER et al. 1989). Five temperature-sensitive mutants were classified in a complementation group initially named $n p l 2$ (nuclear protein localization 2). However, these mutants did not show a general defect in nuclear protein import or export or mRNA export. They did show defects in localization of the large ribosomal subunit (STAGE-ZIMmERMANn et al. 2000).

Using one of the original mutants (PSY8) and a yeast genomic library, TIF51A was cloned by complementation of the temperature-sensitive phenotype (CHIANG 1993). Here, three of these mutants (PSY8, PSY338, and PSY341) were further characterized. These strains were first backcrossed three times to the parental W303 strains to generate a number of new strains containing the same mutated alleles of TIF51A. To determine whether the temperature-sensitive mutations were linked to the TIF51A locus, npl2 strains (PSY1242-PSY1244) 
were crossed to a strain containing the URA3 gene inserted next to TIF51A (PSY1241). The diploids that resulted from these crosses were sporulated and subjected to tetrad analysis. If the mutations present in the $n p l 2$ strains were linked to TIF51A, the temperature-sensitive phenotype of the mutants would never cosegregate with the URA3 gene. For npl2-1, 25 complete asci were analyzed and no temperature-sensitive Ura + spore was observed. The same result was obtained with $n p l 2-2$ and $n p l 2-3$, after analyzing 15 and 17 complete asci, respectively. These results demonstrate that $n p l 2-1, n p l 2-2$, and $n p l 2-3$ are linked to TIF51A. Therefore, the $n p l 2$ mutants presented here contain temperature-sensitive alleles of the gene encoding eIF5A and are henceforth referred to as tif51A-1, tif51A-2, and tif51A-3.

These three TIF5 $1 A$ temperature-sensitive alleles were cloned by PCR into pRS315 (CEN/LEU2) using genomic DNA obtained from the tif $51 A$ strains. To test whether the cloned mutant alleles of TIF51A were functional, we generated a strain in which TIF51A was disrupted. Sporulation of a heterozygous TIF51A/tif51AA::HIS3 diploid revealed that TIF51A is an essential gene since only two viable his ${ }^{-}$spores were obtained in 24 tetrads analyzed. This result agreed with WoHL et al. (1993) and with the isolation of temperature-sensitive alleles of TIF51A. In contrast, another report showed that cells lacking TIF51A grow slowly and become inviable only when TIF51B is also disrupted (SCHNIER et al. 1991). This discrepancy may be due to strain background differences.

The three TIF51A alleles demonstrate varying degrees of temperature sensitivity upon growth at $37^{\circ}$ on rich media, YEPD (Figure 1A). While the allele tif51A-2 displays a moderate reduction in growth at the nonpermissive temperature, alleles tif51A-1 and tif51A-3 display more pronounced growth defects. To determine the time of onset of the growth defect in the tif5 $1 \mathrm{~A}$ mutant strains, midlog phase cultures were monitored at different times after shift to the nonpermissive temperature (Figure 1B). Although tif51A mutant strains showed slightly slower growth than the wild-type strain at $25^{\circ}$ (left), they showed a significant decrease in growth rate by $2-3 \mathrm{hr}$ after shift to $37^{\circ}$ (right). The discrepancy in the relative growth defect between tif51A-1 and tif51A-2 on plates vs. liquid may reflect a growth defect that is overcome after longer incubation times.

To define the mutations in the TIF51A gene present in the tif5 $1 \mathrm{~A}$ temperature-sensitive mutants, genomic DNA was isolated from the tif5 $1 \mathrm{~A}$ strains and the TIF5 $1 \mathrm{~A}$ gene was amplified by PCR. The $0.7-\mathrm{kb}$ fragment containing TIF5 $1 A$ was purified and then sequenced. These mutations were confirmed by sequencing the cloned alleles in pPS1593, -1594, and -1595. A single mutation of the same residue was detected for the tif51A-1 and tif51A-2 alleles. The proline at position 83 was changed to serine (P83S) or leucine (P83L), respectively. Two mutations were mapped in the tif51A-3 allele, a cysteine-
A

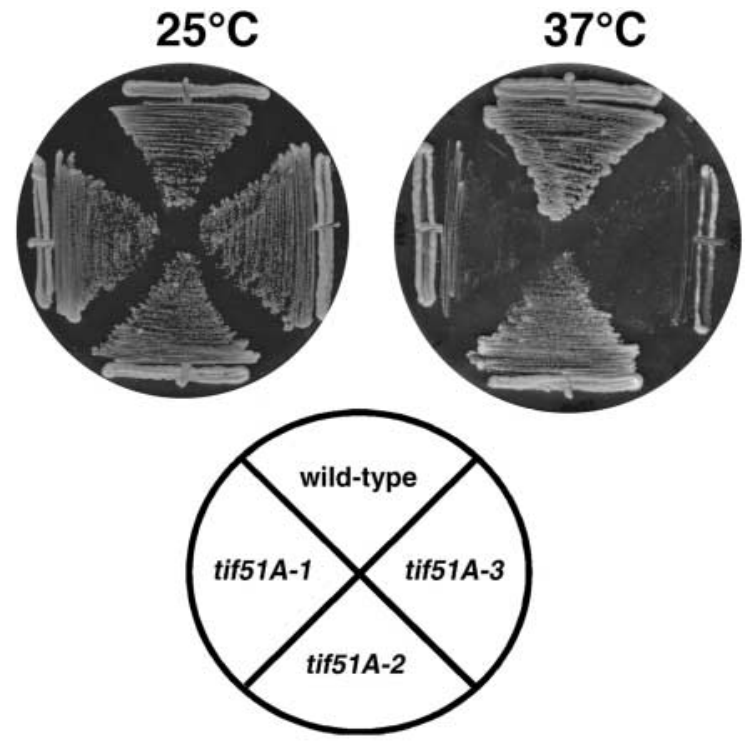

B
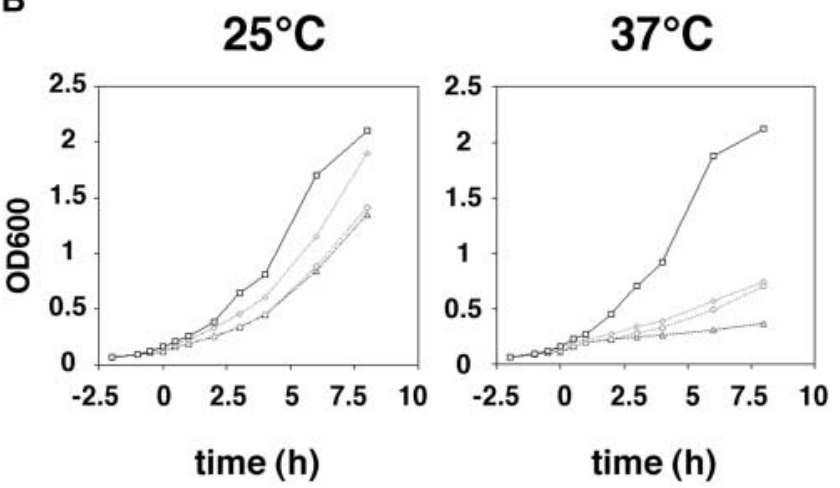

Figure 1.-Temperature sensitivity of tif51A alleles. (A) Temperature sensitivity of tif51A mutant strains: Wild-type (W303), tif51A-1 (PSY1245), tif51A-2 (PSY1248), and tif51A-3 (PSY1249) strains were streaked to rich plates (YEPD) and grown at either $25^{\circ}$ or $37^{\circ}$ for 3-4 days. (B) Strains W303, PSY1245 (tif51A-1), PSY1248 (tif51A-2), and PSY1249 (tif51A-3) were grown at $25^{\circ}$ in rich medium (YEPD) to midlog phase $(2.5 \mathrm{hr})$. The cultures were then split between $25^{\circ}$ and $37^{\circ}$ and growth was monitored for $8 \mathrm{hr}$ by spectrophotometry $\left(\mathrm{OD}_{600 \mathrm{~nm}}\right) .(\square)$ Wild type, $(\diamond)$ tif5 $1 A-1,(\bigcirc)$ tif5 $1 A-2,(\triangle)$ tif51A-3.

to-tyrosine change at position 39 (C39Y) and a glycineto-aspartic acid change at position 118 (G118D).

Two crystal structures of archaebacterial eIF5A proteins have been solved (Кim et al. 1998; РеAт et al. 1998) and the positions of these mutations in the Methanococcus jannaschii eIF5A structure (KIm et al. 1998) are shown (Figure 2). The proline mutated in tif51A-1 and tif51A-2 proteins is at the junction between the two domains of eIF5A. In contrast, the mutations in tif51A-3, both of which are required for temperature sensitivity (data not shown), are found on separate domains of eIF5A. C39Y is found in a $\beta$-sheet 12 residues $\mathrm{N}$-terminal to the hypusinated lysine that is critical for eIF5A function; G118D 


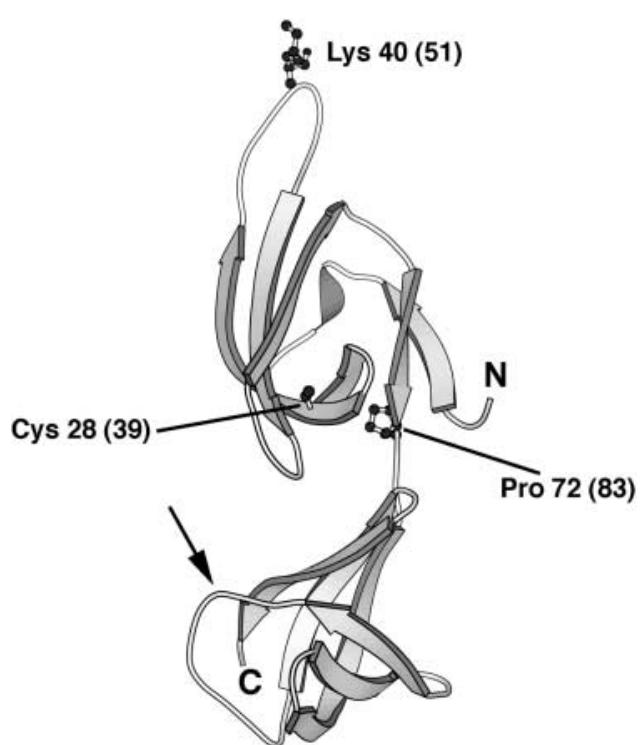

Figure 2.-Lesions in tif5 $1 \mathrm{~A}$ temperature-sensitive alleles. The locations of mutated residues in the eIF5A structure are shown on the archaebacterial eIF5A crystal structure (KIm et al. 1998; yeast eIF5A residue numbers are shown in parentheses). Tif51A-1 and tif51A-2 have mutations at Pro83 and tif51A-3 has mutations at Cys39 and Gly118 in the C-terminal domain loop (arrow). The essential hypusinated lysine is also shown.

is located within a loop in the C-terminal domain. Thus both domains of eIF5A appear to be important for its function.

To determine eIF5A protein levels in the tif5 $1 \mathrm{~A} \mathrm{mu-}$ tant strains, a rabbit polyclonal antiserum against eIF5A was produced using recombinant yeast eIF5A expressed in E. coli. This antiserum was used to detect eIF5A by Western blot in cell lysates prepared from wild-type and temperature-sensitive TIF51A strains grown at the permissive and nonpermissive temperature (Figure 3). At $25^{\circ}$, eIF5A of the expected molecular mass $(\sim 20 \mathrm{kD})$ was detected in the wild-type (WT) and in the tif51A-1 and tif51A-2 strains. In the case of tif51A-3, eIF5A migrates slightly more slowly, due to the G118D mutation in eIF5A in the tif51A-3 strain (data not shown). After a 3-hr shift to $37^{\circ}$, levels of mutant eIF5A proteins are significantly lower than that of the wild-type protein,

\section{tif51A-}

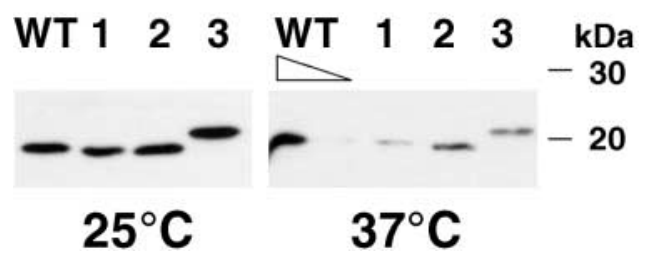

FIGURE 3.-Expression of mutant eIF5A proteins. Samples from cultures in Figure 1B were collected at $3 \mathrm{hr}$ postshift, cells were lysed, and $5 \mu \mathrm{g}$ (or $1 \mu \mathrm{g}$ for the lower dilution of the wild-type culture at $37^{\circ}$ ) of total protein was analyzed by Western blotting with an anti-eIF5A antiserum.

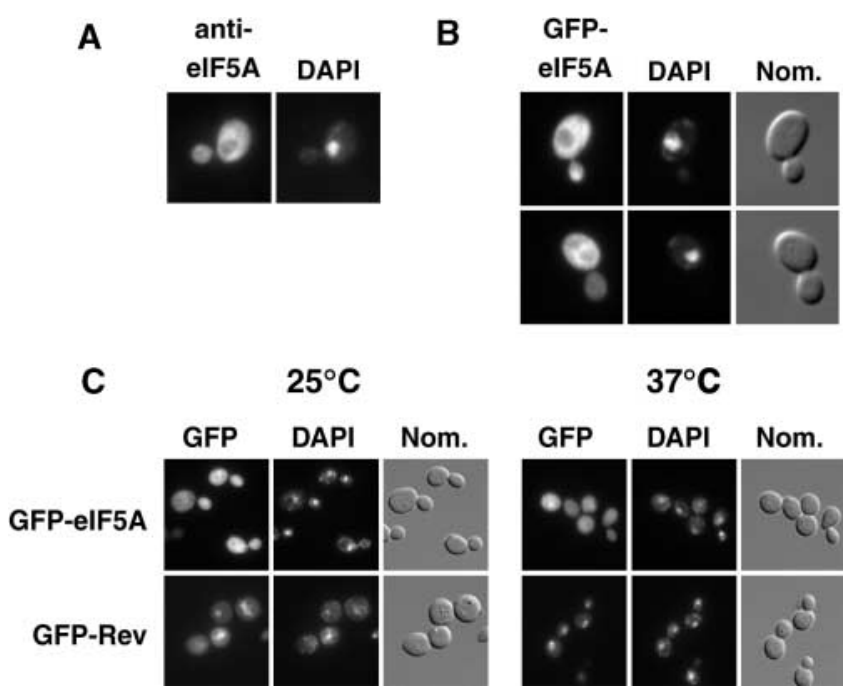

Figure 4.-Localization of wild-type eIF5A. (A) Endogenous eIF5A localization in fixed cells. Wild-type cells (FY23) were grown at $25^{\circ}$ to midlog phase and fixed by incubation with formaldehyde. Cells were placed on polylysine-coated slides and, after permeabilization, incubated first with a rabbit anti-eIF5A polyclonal serum and then with an anti-rabbit fluorescein-conjugated secondary antibody. Localization of eIF5A was then visualized by fluorescence microscopy. (B) GFPeIF5A localization in living cells. A functional GFP-eIF5A fusion protein was expressed in wild-type yeast cells (FY23) under the control of a galactose promoter. Production of the fusion protein was induced for $1-2 \mathrm{hr}$ at $25^{\circ}$ prior to visualization by fluorescence microscopy. (C) Localization of eIF5A and Rev in xpo1-1 cells. Xpo1-1 cells (PSY1105; STADE et al. 1997) were transformed with $2 \mu$ URA3 plasmids containing either GFP-eIF5a (pPS1597) or GFP-Rev (pPS1494) under the control of the inducible GAL promoter. Cells were grown in $2 \%$ raffinose until midlog phase, induced with $2 \%$ galactose for $3-5 \mathrm{hr}$, shifted to glucose, incubated at $25^{\circ}$ or $37^{\circ}$ for $1 \mathrm{hr}$, and fixed, and eIF-5A and REV localization was determined by fluorescence microscopy.

suggesting that these are loss-of-function alleles. Indeed, after $12 \mathrm{hr}$ at $37^{\circ}$, eIF5A mutant protein is no longer detectable by Western blotting (data not shown).

Localization of eIF5A in the yeast $S$. cerevisiae: eIF5A has been proposed to be an export factor for the human immunodeficiency virus (HIV) Rev protein, by virtue of acting as an adapter to the transporter exportin/CRM1 (RuHL et al. 1993; Bevec et al. 1996; Bevec and Hauber 1997; Hofmann et al. 2001). Therefore, we wished to test whether the localization of yeast eIF5A was consistent with this hypothesis, and, if so, whether tif51A mutant alleles affected nuclear export. eIF5A localization was performed initially by indirect immunofluorescence, using formaldehyde-fixed wild-type cells and antieIF5A antiserum (Figure 4A). eIF5A is localized mainly in the cytoplasm with a concentration in the perinuclear region. A comparison of the eIF5A localization to $4^{\prime}, 6-$ diamidino-2-phenylindole (DAPI) staining of nuclei reveals that only minor amounts of eIF5A are found in the nucleus.

To ascertain whether this localization reflected eIF5A 
distribution in live cells, TIF5A was inserted downstream of a galactose-inducible green fluorescent protein gene. This plasmid produces functional eIF5A in that it restores the ability of tif51A-1 to grow at the restrictive temperature after galactose induction (data not shown). This plasmid was transformed into a wild-type strain and after 1-2 hr induction with galactose, GFP-eIF5A localization was determined by fluorescence microscopy (Figure 4B). As expected, GFP-eIF5A was detected predominantly in the cytoplasm with a stronger signal in the perinuclear region (Figure 4B, left). These results conclusively show that eIF5A is a cytoplasmic protein and accumulates in the perinuclear region.

If eIF5A were to facilitate HIV Rev export by binding both Rev and the Xpo1/Crm1 exporter, export of eIF5A itself would be expected to be blocked by mutations in the export machinery. To test if eIF5A is exported by Xpo1/Crm1, its localization was monitored in xpo1-1 cells, which are temperature sensitive for export by this pathway. Xpo1-1 cells carrying GFP-eIF5A or GFP-Rev on $2 \mu U R A 3$ plasmids under the galactose-inducible promoter were grown to midlog phase and then induced with galactose for $3 \mathrm{hr}$, shifted to $37^{\circ}$ for $1 \mathrm{hr}$, fixed, and then visualized by fluorescence microscopy (Figure 4C). GFP-eIF5A localization was predominantly cytoplasmic in xpo1-1 cells at $37^{\circ}$. Comparison with DAPI staining shows no marked increase in nuclear localization of eIF5A, which would be expected if eIF5A shuttled in an Xpo1-dependent manner, suggesting that eIF5A is not exported by Xpo1 in yeast. In contrast, GFP-Rev showed a marked accumulation of fluorescent signal in nuclei of xpo1-1 cells after $1 \mathrm{hr}$ at the nonpermissive temperature (Figure 4C).

To further test the dependence of Rev export upon eIF5A, GFP-Rev localization was examined in strains containing the TIF51A temperature-sensitive alleles. After a 3-hr shift to the nonpermissive temperature, GFP-Rev displayed cytoplasmic localization similar to that seen in the wild-type control (Figure 5). The slight increase in signal in the mutant alleles after temperature shift does not coincide with the nucleus as determined by DAPI staining (Figure 5). These data are consistent with a recent study in mammalian cells that revealed that exportin 4, rather than CRM1, exports eIF5A (Lipowsky et al. 2000). Since no yeast homolog of exportin 4 exists, eIF5A localization was tested in a battery of strains with mutations in putative transport proteins. None of these strains showed a nuclear accumulation of eIF5A (data not shown), suggesting either that yeast eIF5A does not shuttle between the nucleus and the cytoplasm or that its exporter has no homology to known transport proteins. These data, in combination with the finding that Rev export is not blocked in tif51A mutant strains, argue against the hypothesis that Rev export by Xpo1/CRM is mediated by eIF5A.

mRNA decay defect of tif51A alleles: eIF5A has also been proposed to play a role in mRNA decay (ZuK $25^{\circ} \mathrm{C}$

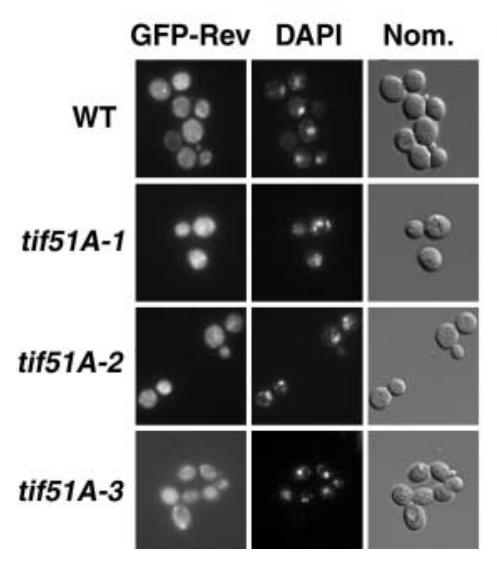

$37^{\circ} \mathrm{C}$

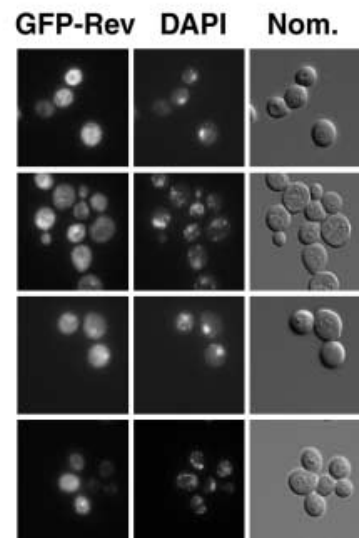

FiguRE 5.-Localization of GFP-Rev in tif5 1A mutant strains. Wild-type (W303), tif5 1A-1 (PSY1245), tif5 1A-2 (PSY1248), and tif51A-3 (PSY1249) strains were transformed with a $2 \mu$ URA3 plasmid containing GFP-Rev (pPS1494) under the control of the inducible GAL promoter. Cells were prepared as in Figure $4 \mathrm{C}$ with a temperature shift to $37^{\circ}$ for $3 \mathrm{hr}$ and visualized by fluorescence microscopy.

and Jacobson 1998). To test whether the tif51A alleles described above affect mRNA stability at the nonpermissive temperature, wild-type or mutant strains were grown for $4 \mathrm{hr}$ at $37^{\circ}$, transcription was inhibited, and samples were taken at several times post-transcription (Figure $6)$. Northern blot analysis with a probe against the moderately stable $H H T 2$ mRNA shows a significant decrease in the levels of these RNAs in wild-type cells over the course of the assay as compared to the 25S rRNA loading control (Figure 6, TIF51A). However, in tif51A-1 and

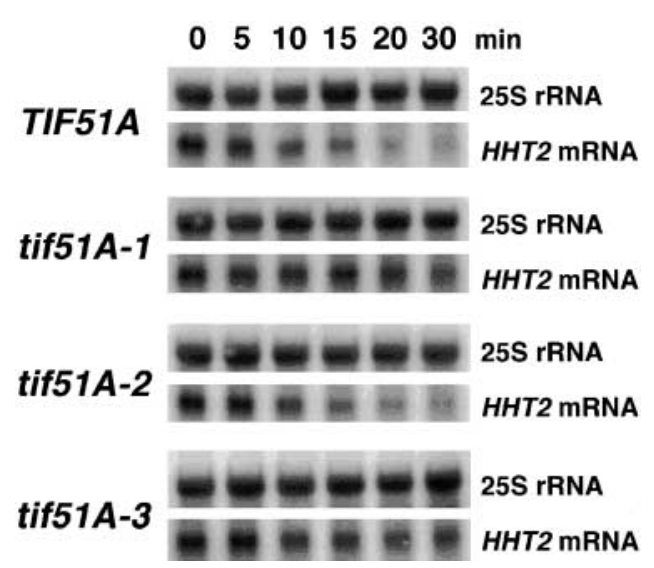

FIGURE 6.-mRNA decay defect in tif5 $1 A$ temperature-sensitive alleles. Northern blot analysis of HHT2 mRNA. Following incubation at $37^{\circ}$ for $4 \mathrm{hr}$, thiolutin was added to cultures to the final concentration of $20 \mu \mathrm{g} / \mathrm{ml}$ and cell samples were collected at the times indicated. Total RNA was extracted and analyzed by Northern blotting using probes complementary to the $25 \mathrm{~S}$ rRNA and to the HHT2 mRNA. Quantitation of the 25S rRNA served as an internal control to visualize the amount of total RNA loaded in each lane. Blots were analyzed and bands quantitated by using a phosphorimager. 
TABLE 4

Multicopy suppressors of the temperature-sensitive mutant tif51A-1

\begin{tabular}{lccl}
\hline Clone & $\begin{array}{c}\text { No. of } \\
\text { isolates }\end{array}$ & Chromosome & \multicolumn{1}{c}{ Suppressor } \\
\hline 1 & 8 & XV & YOR137C (SIA1) \\
2 & 2 & II & PKC1 \\
3 & 2 & XIV & WSC2 \\
4 & 1 & V & PAB1 \\
5 & 1 & XV & WSC1/SLG1/HCS77 \\
6 & 1 & XV & WSC3 \\
\hline
\end{tabular}

tif51A-3 strains the HHT2 RNA is stabilized, with levels slightly higher than those in wild-type cells at 15-30 min post-inhibition (Figure 6). The HHT2 RNA level in tif51A-2 cells is similar to that in wild-type cells. Similar results were obtained by probing the $P A B 1$ transcript (data not shown). Cells submitted to heat shock for a shorter period of time $\left(2 \mathrm{hr}\right.$ at $\left.37^{\circ}\right)$ did not display significant stabilization of CYH2, PAB1, and HHT2 mRNAs (data not shown).

Suppression of the temperature-sensitive phenotype of tif51A-1: To expand our understanding of the function of eIF5A, we wished to identify other genes that encode proteins that work similarly or together with eIF5A, and therefore we performed a high-copy suppressor screen. A yeast genomic library was transformed into the tif51A-1 strain and transformants that could grow at $36^{\circ}$ were selected. Twenty-three plasmids that still suppressed temperature sensitivity after retransformation into tif5 1A-1 were characterized by DNA sequencing. Six clones, representing 15 of these plasmids, were selected and used to define the ORF that suppresses the temperature-sensitive phenotype of tif51A-1. These clones are presented in Table 4 . One clone contained the entire PKC1 gene, which was cloned twice in this screen, without flanking ORFs. Subcloning revealed the other suppressing ORFs to be the following: YOR137C, WSC2, WSC1, WSC3, and PAB1. To eliminate partial flanking ORFs, these five genes were also cloned by PCR and the constructs tested for suppression of the temperature-sensitive phenotype of tif51A-1 strain. Figure 7 shows that the ability of tif51A-1 to grow at $36^{\circ}$ was restored by expression of these genes in high copy. In addition, all tif51A-1 suppressors were allele specific, as they were unable to rescue growth of tif5 $1 A-3$ at high temperatures (data not shown). The plate phenotype of tif51A-2 at $36^{\circ}$ was too weak to test suppression in this manner.

To test whether the two most-well-studied suppressor proteins, poly(A)-binding protein (Pab1) and protein kinase $\mathrm{C}$ ( $\mathrm{Pkc1}$ ), acted by increasing the levels of mutant eIF5A protein, mutant strains bearing the multicopy $P A B 1$ and $P K C 1$ plasmids were grown at $25^{\circ}$ or $37^{\circ}$ for 3 $\mathrm{hr}$ and eIF5A levels were monitored by Western blotting
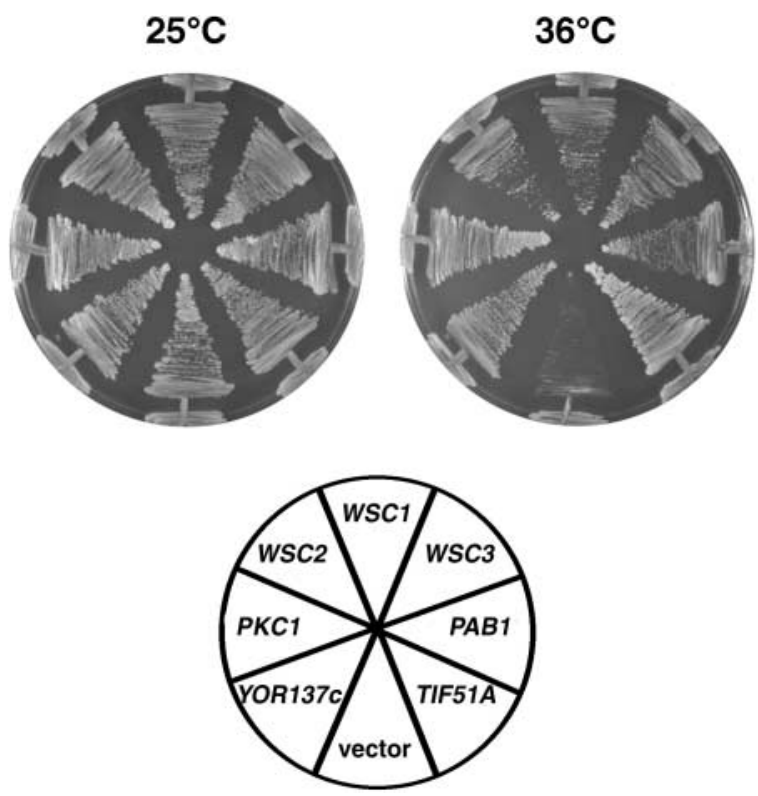

Figure 7.-High-copy suppressors of tif51A-1 temperature sensitivity. tif51A-1 strain PSY1252 was transformed with a $2 \mu$ URA3 library of plasmids and transformants were screened for restoration of growth at $36^{\circ}$. Candidates that still suppressed after plasmid rescue and retransformation into PSY1252 were restreaked to plates lacking uracil at $25^{\circ}$ and $36^{\circ}$. Wild-type TIF5 $1 A$ and the $2 \mu$ URA3 vector, positive and negative controls, are also shown.

(Figure 8). Overexpression of $P A B 1$ and PKC1 did not have a significant effect on steady-state levels of eIF5A at either permissive or nonpermissive temperatures. The slight increase in eIF5A-3 levels in the presence of excess Pkc1 was not reproducible.

Connections between PKC1 signaling and eIF5A: To examine the importance of PKC1 signaling in tif $51 \mathrm{~A}$ mutant strains, we tested whether a kinase-inactive form of PKC1 could suppress the tif51A-1 temperature sensitivity. Strain PSY1245 was transformed with high-copy

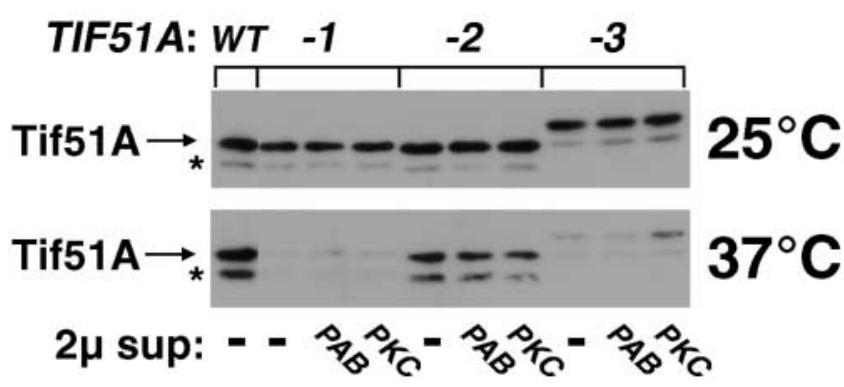

Figure 8.-eIF5A protein levels in the presence of highcopy PAB1 and PKC1. W303 bearing high-copy vectors pRS426 and PSY1245 (tif51A-1); PSY1248 (tif51A-2); and PSY1249 (tif51A-3) bearing pRS426, pPS1600 (PKC1), or pPS1601 (PAB1) were grown at $25^{\circ}$ to midlog phase and then shifted to $37^{\circ}$ or left at $25^{\circ}$ for $3 \mathrm{hr}$. Cells were lysed and $5 \mu \mathrm{g}$ total protein was analyzed by anti-eIF5A Western blotting as in Figure 3. The asterisk denotes a common degradation product of eIF5A (KANG et al. 1993). 


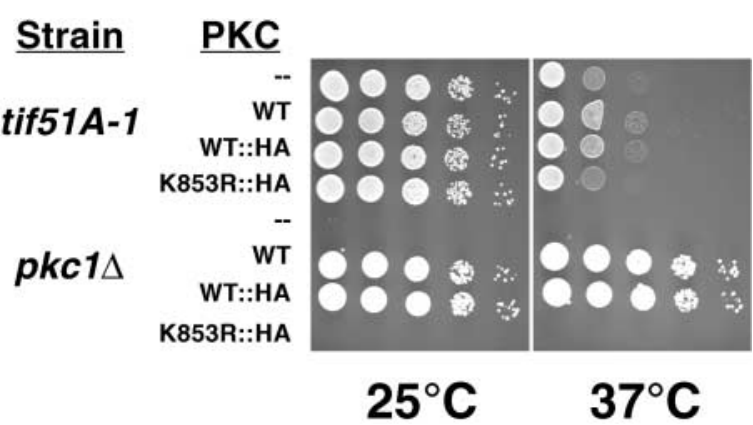

FIGURE 9.-PKC kinase activity is required for suppression of tif51A-1 temperature sensitivity. Dilutions of PSY1245 (tif5 1A-1) and DL376 ( $p k c 1 \Delta$ ) strains bearing plasmids pRS426 (-), pPS1600 (WT), pPS2440 (WT::HA), and pPS2441 (K853R::HA) were grown for 2 days on plates lacking uracil and sorbitol at $25^{\circ}$ and $37^{\circ}$.

plasmids encoding wild-type Pkc1, HA-tagged wild-type $\mathrm{Pkc1}$, or HA-tagged Pkc1 with a lysine-to-arginine change in the active site (K853R). Serial dilutions of each transformed strain were then plated at $25^{\circ}$ or $37^{\circ}$ (Figure 9). Whereas the ability of PKC1 to suppress tif51A-1 temperature sensitivity was not impaired by the addition of an HA tag (WT vs. WT::HA), the active site mutation (K853R::HA) eliminated suppression. Growth of the $p k c 1 \Delta$ strain, which requires PKC activity, is shown as a control (WATANABE et al. 1994). Therefore, kinase activity of $P K C 1$ is required both for signaling and for growth of the tif51A-1 strain, indicating a functional link between eIF5A and PKC1 signal transduction.

Although $P K C 1$ is involved in multiple signaling pathways in yeast, the additional isolation of three WSC genes as high-copy suppressors of tif51A-1 suggested a connection between eIF5A and a specific pathway involved in stress response and maintenance of cell wall integrity (for review see Heinisch et al. 1999). Deletion of PKC1 or WSC1 results in cell wall defects and cell lysis on media lacking an osmotic stabilizer (PARAvicini et al. 1992; Verna et al. 1997). To determine whether the temperature sensitivity of tif5 $1 \mathrm{~A}$ mutant strains might reflect a defect in cell wall integrity, dilutions of each strain were grown at $37^{\circ}$ on rich media without or with $1 \mathrm{~m}$ sorbitol to lend osmotic stability (Figure 10). The addition of sorbitol significantly increased the ability of tif51A-1 and tif5 $1 A-3$ strains to grow at $37^{\circ}$ and completely suppressed the growth defect of tif51A-2. Growth of a strain lacking PKC1, which requires an osmotic stabilizer at all temperatures, is shown as a control (Levin and BARTLETT-Heubusch 1992). These results suggest that the ability of PKC1 and WSC genes to suppress the temperature sensitivity of tif $51 A-1$ is due to their roles in maintaining cell wall integrity.

\section{DISCUSSION}

In spite of two decades of research on eIF5A, the role of this ubiquitous protein remains mysterious. In this

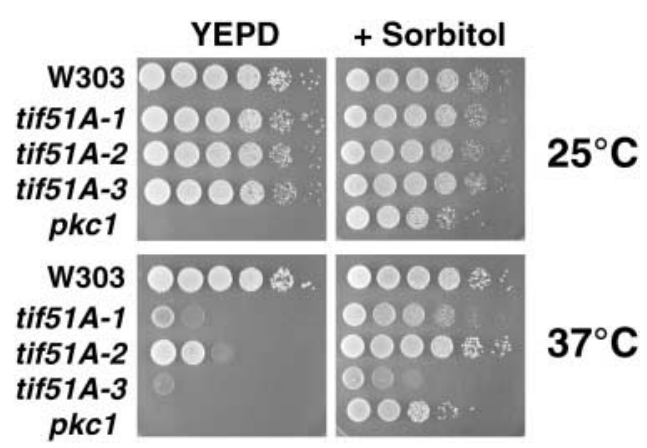

FIGURE 10.-Temperature sensitivity of tif51A mutant strains is partially suppressed by sorbitol. Dilutions of wildtype (W303), tif51A-1 (PSY1245), tif51A-2 (PSY1248), tif51A-3 (PSY1249), and pkc1s (DL376; LEVIN and BARTLETT-HeUBUSCH 1992) strains were grown for 2 days at $25^{\circ}$ or $37^{\circ}$ on YEPD plates with or without $1 \mathrm{M}$ sorbitol as an osmotic stabilizer.

report, three temperature-sensitive alleles of TIF51A were characterized (tif51A-1, tif51A-2, and tif51A-3). While mRNA decay experiments indicated that the stronger mutations led to stabilization of mRNAs, localization studies of wild-type eIF5A suggested that this protein is unlikely to be involved in HIV Rev export. The tif51A-1 allele was used to contribute further to the search for a function for this highly conserved protein. Screening of a $2 \mu$ plasmid library containing genomic DNA uncovered six genes that allowed growth of tif51A-1 strains at high temperature. Further experiments supported the importance of the PKC/WSC signaling pathway for cell wall integrity in tif51A-1 mutant cells.

In fluorescence microscopic experiments, eIF5A was detected primarily in the cytoplasm with a concentration in the perinuclear region (Figure 4). This result agrees with the subcellular localization of mammalian eIF5A (SHi et al. 1996b, 1997). RuHL et al. reported that a substantial fraction of eIF5A was also present in the nucleus and suggested that eIF5A was a shuttling protein involved in HIV Rev export (RUHL et al. 1993; Bevec et al. 1996; Bevec and Hauber 1997). However, in yeast, eIF5A is not mislocalized to the nucleus in an xpo1-1 strain, a temperature-sensitive mutant of the export receptor for Rev and other proteins that contain leucinerich nuclear export signals (NESs), nor does eIF5A itself have a canonical NES (STADE et al. 1997, Figure 4). Indeed, exportin 4, rather than CRM1, was recently found to mediate eIF5A export in mammalian cells (Lipowsky et al. 2000). Thus, our data from S. cerevisiae support the cytoplasmic localization of eIF5A, perhaps associated with the ER/ribosomes as suggested by its concentration in the perinuclear region. Furthermore, our data do not support the hypothesis of eIF5A being involved in the export of NES-containing proteins through the export receptor Xpo1p/Crm1p.

The identification of conditional tif51A alleles in a screen for mislocalization of a nuclear localization se- 
quence (NLS)-reporter protein initially would seem to suggest that eIF5A is crucial for nuclear import (SADLER et al. 1989; CHIANG 1993). The reporter protein in this screen contained an SV40 NLS fused to cytochrome $c_{1}$ (Cyt1). Thus, in a strain with a null allele of CYT1, growth on glycerol media requires the mislocalization of the normally nuclear NLS-cytochrome c protein to mitochondria. The npl2/tif51A complementation group of mutant strains grew on glycerol plates at permissive temperature; however, the NLS reporter proteins still localized to the nucleus as detected by immunofluorescence microscopy (CHIANG 1993). In addition, strains bearing the mutant tif51A alleles did not mislocalize the nuclear protein Npl3p, a cytoplasmic NLS-NES-GFP fusion protein, mRNA, or the mutant eIF5A proteins themselves (data not shown). These contradictory results suggest that the mechanism by which mutations in TIF51A allow growth on a nonfermentable carbon source does not involve redirecting the majority of cytochrome $\mathrm{c}_{1}$ to mitochondria. These mutations may alter the translation or decay rate of the CYT1 mRNA and thereby increase the production of the fusion protein, perhaps allowing a minor fraction to reach the mitochondria to allow growth.

A high-copy suppressor screen with the tif51A-1 allele revealed six genes that could suppress the temperature sensitivity of this mutant. These suppressors are $P A B 1$, YOR137C, PKC1, WSC1, WSC2, and WSC3. The most frequent suppressor in the screen, YOR137C [named here suppressor of eIF5A (SIA1)], encodes a protein with a peptide signal for membrane localization and was recently associated with activation of the yeast plasma membrane $\mathrm{H}^{+}$-ATPase by glucose (DE LA Fuente et al. 1997). Although the fluorescence pattern of a GFPSif51A fusion protein, cytoplasmic and concentrated in the perinuclear region, is similar to that of eIF5A (data not shown), it is not clear how overexpression of Sif51Ap could suppress tif51A-1 temperature sensitivity.

Another high-copy suppressor of tif51A-1, PAB1 has been shown to be involved in multiple aspects of RNA metabolism, including 3 '-end processing, translation, and mRNA decay. The yeast gene, $P A B 1$, is essential but the lethality caused by deletion of $P A B 1$ can be suppressed by mutations in a number of other genes, including genes that encode components of the translational and mRNA degradation machinery (SACHS and DAVIS 1989, 1990; Caponigro and PARker 1995; Boeck et al. 1998; Bonnerot et al. 2000). Pab1 participates in the length control of poly(A) tails of messenger RNAs in the yeast nucleus (AMrani et al. 1997; Kessler et al. 1997; Minvielle-Sebastia et al. 1997), and the poly(A) tail enhances the translation of mRNAs (JACOBSON and FAVREAU 1983; Galili et al. 1988; Munroe and Jacobson 1990). This translational enhancement is mediated by the binding of Pablp to initiation factor eIF-4G, which is part of the mRNA cap-binding complex eIF-4F (TARUN et al. 1997). The intimate connections between translation and mRNA decay are underscored by the roles of these proteins in both processes: binding of Pab1p stabilizes mRNA in a translation-dependent manner (Coller et al. 1998) and mutations in eIF-4F complex genes as well as in $P A B 1$ result in destabilization of mRNA (Schwartz and Parker 1999; Brown et al. 2000).

Like Pab1, eIF5A has been implicated in both translation and mRNA decay. Although eIF5A was first thought to be a translation initiation factor (BENNE and HerSHEY 1978; PARK et al. 1993), a temperature-sensitive mutant of TIF51A (ts1159) decreases the decay rate of several mRNAs tested and results in a twofold accumulation of uncapped URA5 mRNA (Zuk and JACOBSON 1998). This mutant also displays slowed translation, as was shown in the eIF5A depletion studies (KANG and Hershey 1994; Zuk and Jacobson 1998). Here we have shown that tif51A-1 and tif51A-3 alleles result in mRNA decay defects at the nonpermissive temperature (Figure $5)$, although the rate of mRNA stabilization seen in the mutants tif51A-1 and tif51A-3 is less drastic than that observed in the strain ts1159 (ZuK and JACOBSon 1998). No effect on mRNA decay was observed in the mutant strain tif51A-2. These results support the idea that the effects on mRNA decay are allele specific. Significant mRNA stabilization is not detected until after $4 \mathrm{hr}$ of heat shock, suggesting the possibility that secondary effects are being measured. Furthermore, these results suggest that the suppression of tif51A-1 temperature sensitivity by overexpression of $P A B 1$ may reflect complementary roles of eIF-5A and Pab1 in mRNA decay.

The high-copy suppressor focused on in this work, $P K C 1$, is the yeast homolog of the metazoan $P K C$ gene and encodes a regulator of one of the four mitogenactivated protein-kinase cascades characterized so far in S. cerevisiae (Posas et al. 1998). Pkc1-signaling pathways can be activated by hypotonic and heat shock and they are involved with cell cycle control and cell wall biosynthesis (Levin et al. 1990; Madden et al. 1997; Posas et al. 1998). Remarkably, three other suppressors isolated simultaneously are upstream regulators of the cell wall integrity signaling pathway: WSC1 (SLG1 or HCS77), WSC2, and WSC3 (GRAY et al. 1997; VERNA et al. 1997; JАСОву et al. 1998).

Although PKC signaling has not been shown to have a direct role in mRNA translation or decay, recent studies have revealed the importance of $P K C /$ WSC signaling in the regulation of ribosome synthesis (NIERRAs and WARNER 1999; Li et al. 2000). Ribosomal RNA and ribosomal protein mRNA transcription are inhibited during the stress response caused by a secretion block and this downregulation requires $P K C 1$ and the WSC genes. Several results also point to the possibility that eIF5A may have a role in regulating ribosome synthesis. At high temperature two of the mutant strains characterized in this study, tif5 1A-1 and tif5 1A-2 (referred to as $n p l 2-1$ and $n p l 2-2)$, were found to mislocalize the large ribosomal 
subunit protein L11 fused to GFP in 10-40\% of cells, reflecting a defect in either ribosome assembly or export (StAGe-Zimmermann et al. 2000). In permeabilized cell assays, purified eIF5A was shown to accumulate in nucleoli, the site of ribosome synthesis (Lipowsky et al. 2000). The initial identification of eIF5A as a ribosomeassociated factor (Kemper et al. 1976; Benne and HerSHEY 1978) and the $30 \%$ decrease in translation found in cells depleted of eIF5A (KANG and Hershey 1994) may reflect the involvement of eIF5A in ribosome synthesis, rather than a direct role in translation.

The ability of tif51A-1 temperature sensitivity to be partially suppressed either by overexpression of $P K C$ or WSC genes (Figure 6) or by the addition of sorbitol (Figure 9) suggests that eIF5A may act either in the PKC pathway for cell integrity or in a parallel pathway. eIF5A is phosphorylated in vivo, but the kinase responsible for this nonessential modification has not been identified. PKC1 overexpression may suppress tif51A-1 by increasing phosphorylation of the mutant protein. Alternatively, PKC1 could phosphorylate a protein that interacts with eIF5A and that is important for its function. One candidate eIF5A-interacting protein is deoxyhypusine synthase, the essential enzyme that catalyzes the first step in the lysine-to-hypusine modification (KANG et al. 1995; SASAKi et al. 1996). This protein has been shown to be phosphorylated specifically by PKC in vitro (KANG and CHUNG 1999) and contains three potential target $\mathrm{S} / \mathrm{T}$ residues with basic residues on both sides. It is also intriguing to note that Pkclp is an upstream regulator of the SBF transcription factor, which is a regulator of the G1-to-S phase (MADDEN et al. 1997), and that eIF5A has been implicated in the translation of mRNAs involved in the same cell cycle transition (Hanauske-Abel et al. 1995). The exact mechanism of PKC suppression will be the focus of future investigation.

The isolation of PAB1, PKC1, and the WSC genes as high-copy suppressors of tif51A-1 points to different roles for eIF5A in RNA metabolism from mRNA decay to ribosome synthesis. The allele specificity of suppression suggests that eIF5A may have more than one important role in the cell, leading to functional differences between the alleles. It is interesting to note that PKC1 was identified in a Pablp two-hybrid screen (Mangus et al. 1998). The genetic interactions of these genes with TIF51A suggest that these three proteins are intimately associated, but further experiments will be necessary to clarify these interactions. Thus, although the precise function of eIF5A remains an open question, the data presented in this report suggest that eIF5A acts in multiple steps of RNA metabolism. Future research will help define the exact roles played by these proteins in posttranscriptional regulation.

We are grateful to Dr. Sung-Hou Kim for use of the M. jannaschii eIF5A crystal structure and Dr. David Levin for PKC1 reagents. We thank Valerie Weiss for her help in analyzing the crystal structure of
eIF5A and Allyson Hatton and Tracy Stage-Zimmermann for critical reading of the manuscript. Sandro Valentini thanks Mario H. Bengtson and Patricia Munerato for technical assistance. This work was supported by grants to S.R.V. and C.C.O. from Fundação de Amparo a Pesquisa do Estado de São Paulo (FAPESP), a training grant from the National Eye Institute to J.M.C., a National Institutes of Health grant to P.A.S., and a National Institutes of Health postdoctoral fellowship to A.E.M.

\section{LITERATURE CITED}

Amrani, N., M. Minet, M. Le Gouar, F. Lacroute and F. Wyers, 1997 Yeast Pab1 interacts with Rna15 and participates in the control of the poly(A) tail length in vitro. Mol. Cell. Biol. 17: 3694-3701.

Baudin, A., O. Ozier-Kalogeropoulos, A. Denouel, F. Lacroute and C. Cullin, 1993 A simple and efficient method for direct gene deletion in Saccharomyces cerevisiae. Nucleic Acids Res. 21: 3329-3330.

Benne, R., and J. W. Hershey, 1978 The mechanism of action of protein synthesis initiation factors from rabbit reticulocytes. J. Biol. Chem. 253: 3078-3087.

Bevec, D., and J. Hauber, 1997 Eukaryotic initiation factor 5A activity and HIV-1 Rev function. Biol. Signals 6: 124-133.

Bevec, D., H. Klier, W. Holter, E. Tschachler, P. Valent et al., 1994 Induced gene expression of the hypusine-containing protein eukaryotic initiation factor $5 \mathrm{~A}$ in activated human $\mathrm{T}$ lymphocytes. Proc. Natl. Acad. Sci. USA 91: 10829-10833.

Bevec, D., H. Jaksche, M. Oft, T. Wohl, M. Нimmelspach et al., 1996 Inhibition of HIV-1 replication in lymphocytes by mutants of the Rev cofactor eIF-5A. Science 271: 1858-1860.

Boeck, R., B. Lapeyre, C. E. Brown and A. B. Sachs, 1998 Capped mRNA degradation intermediates accumulate in the yeast $s p b 8-2$ mutant. Mol. Cell. Biol. 18: 5062-5072.

Bonnerot, C., R. Boeck and B. Lapeyre, 2000 The two proteins Patlp (Mrt1p) and Spb8p interact in vivo, are required for mRNA decay, and are functionally linked to Pablp. Mol. Cell. Biol. 20: $5939-5946$.

Brown, J. T., X. YANG and A. W. Johnson, 2000 Inhibition of mRNA turnover in yeast by an $x r n 1$ mutation enhances the requirement for eIF4E binding to eIF4G and for proper capping of transcripts by Ceglp. Genetics 155: 31-42.

Caponigro, G., and R. Parker, 1995 Multiple functions for the poly(A)-binding protein in mRNA decapping and deadenylation in yeast. Genes Dev. 9: 2421-2432.

Chen, K. Y., and A. Y. Liv, 1997 Biochemistry and function of hypusine formation on eukaryotic initiation factor 5A. Biol. Signals 6: $105-109$

Chen, Z. P., Y. P. Yan, Q. J. Ding, S. Knapp, J. A. Potenza et al., 1996 Effects of inhibitors of deoxyhypusine synthase on the differentiation of mouse neuroblastoma and erythroleukemia cells. Cancer Lett. 105: 233-239.

Chiang, A., 1993 Isolation and characterization of mutants that affect nuclear protein localization. Ph.D. Thesis, Princeton University, Princeton, NJ.

Christianson, T. W., R. S. Sikorski, M. Dante, J. H. Shero and P. Hieter, 1992 Multifunctional yeast high-copy-number shuttle vectors. Gene 110: 119-122.

Coller, J. M., N. K. Gray and M. P. Wickens, 1998 mRNA stabilization by poly(A) binding protein is independent of poly(A) and requires translation. Genes Dev. 12: 3226-3235.

Connelly, C., and P. Hieter, 1996 Budding yeast SKP1 encodes an evolutionarily conserved kinetochore protein required for cell cycle progression. Cell 86: 275-285.

de la Fuente, N., A. M. Maldonado and F. Portillo, 1997 Yeast gene $Y O R 137 c$ is involved in the activation of the yeast plasma membrane H+-ATPase by glucose. FEBS Lett. 420: 17-19.

Galili, G., E. E. Kawata, L. D. Smith and B. A. Larkins, 1988 Role of the 3 -poly(A) sequence in translational regulation of mRNAs in Xenopus laevis oocytes. J. Biol. Chem. 263: 5764-5770.

Gray, J. V., J. P. Ogas, Y. Kamada, M. Stone, D. E. Levin et al., 1997 A role for the Pkc1 MAP kinase pathway of Saccharomyces cerevisiae 
in bud emergence and identification of a putative upstream regulator. EMBO J. 16: 4924-4937.

Hanauske-Abel, H. M., M. H. Park, A. R. Hanauske, A. M. Popowicz, M. LALANDE et al., 1994 Inhibition of the G1-S transition of the cell cycle by inhibitors of deoxyhypusine hydroxylation. Biochim. Biophys. Acta 1221: 115-124.

Hanauske-Abel, H. M., B. Slowinska, S. Zagulska, R. C. Wilson, L. Staiano-Coico et al., 1995 Detection of a sub-set of polysomal mRNAs associated with modulation of hypusine formation at the G1-S boundary. Proposal of a role for eIF-5A in onset of DNA replication. FEBS Lett. 366: 92-98.

Heinisch, J. J., A. Lorberg, H. P. Schmitz and J. J. Jacoby, 1999 The protein kinase C-mediated MAP kinase pathway involved in the maintenance of cellular integrity in Saccharomyces cerevisiae. Mol. Microbiol. 32: 671-680.

Henderson, B. R., and P. Percipalle, 1997 Interactions between HIV Rev and nuclear import and export factors: the Rev nuclear localisation signal mediates specific binding to human importinbeta. J. Mol. Biol. 274: 693-707.

Henry, M. F., and P. A. Silver, 1996 A novel methyltransferase (Hmtlp) modifies poly(A)+-RNA-binding proteins. Mol. Cell. Biol. 16: 3668-3678.

Hofmann, W., B. Reichart, A. Ewald, E. Muller, I. Schmitt et al., 2001 Cofactor requirements for nuclear export of Rev response element (RRE)- and constitutive transport element (CTE)-containing retroviral RNAs. An unexpected role for actin. J. Cell Biol. 152: 895-910.

Jacobson, A., and M. Favreau, 1983 Possible involvement of poly(A) in protein synthesis. Nucleic Acids Res. 11: 6353-6368.

Jacoby, J. J., S. M. Nilius and J. J. Heinisch, 1998 A screen for upstream components of the yeast protein kinase C signal transduction pathway identifies the product of the SLG1 gene. Mol. Gen. Genet. 258: 148-155.

Kahana, J. A., and P. A. Silver, 1996 Use of the A. victoria green fluorescent protein to study protein dynamics in vivo, pp. 9.7.2229.27.28 in Current Protocols in Molecular Biology, edited by F. M. Ausubel, R. Brent, R. E. Kingston, D. D. Moore, J. G. Seidman et al. John Wiley \& Sons, New York.

Kang, H. A., and J. W. Hershey, 1994 Effect of initiation factor eIF-5A depletion on protein synthesis and proliferation of Saccharomyces cerevisiae. J. Biol. Chem. 269: 3934-3940.

Kang, H. A., H. G. Schwelberger and J. W. Hershey, 1993 Translation initiation factor eIF-5A, the hypusine-containing protein, is phosphorylated on serine in Saccharomyces cerevisiae. J. Biol. Chem. 268: 14750-14756.

KANG, K. R., and S. I. ChUnG, 1999 Characterization of yeast deoxyhypusine synthase: PKC-dependent phosphorylation in vitro and functional domain identification. Exp. Mol. Med. 31: 210-216.

Kang, K. R., E. C. Wolff, M. H. Park, J. E. Folk and S. I. Chung, 1995 Identification of YHR068w in Saccharomyces cerevisiae chromosome VIII as a gene for deoxyhypusine synthase. Expression and characterization of the enzyme. J. Biol. Chem. 270: 1840818412.

Kemper, W. M., K. W. Berry and W. C. Merrick, 1976 Purification and properties of rabbit reticulocyte protein synthesis initiation factors M2Balpha and M2Bbeta. J. Biol. Chem. 251: 5551-5557.

Kessler, M. M., M. F. Henry, E. Shen, J. Zhao, S. Gross et al., 1997 Hrpl, a sequence-specific RNA-binding protein that shuttles between the nucleus and the cytoplasm, is required for mRNA 3'-end formation in yeast. Genes Dev. 11: 2545-2556.

Kim, K. K., L. W. Hung, H. Үoкота, R. Kim and S. H. Kiм, 1998 Crystal structures of eukaryotic translation initiation factor $5 \mathrm{~A}$ from Methanococcus jannaschii at 1.8 Å resolution. Proc. Natl. Acad. Sci. USA 95: 10419-10424.

Klier, H., T. Wohl, C. Eckerskorn, V. Magdolen and F. LottsPEICH, 1993 Determination and mutational analysis of the phosphorylation site in the hypusine-containing protein Hyp2p. FEBS Lett. 334: 360-364.

Lee, M. S., M. Henry and P. A. Silver, 1996 A protein that shuttles between the nucleus and the cytoplasm is an important mediator of RNA export. Genes Dev. 10: 1233-1246.

Levin, D. E., and E. Bartlett-Heubusch, 1992 Mutants in the $S$ cerevisiae PKC1 gene display a cell cycle-specific osmotic stability defect. J. Cell Biol. 116: 1221-1229.

Levin, D. E., F. O. Fields, R. Kunisawa, J. M. Bishop and J. Thorner,
1990 A candidate protein kinase C gene, PKC1, is required for the $S$. cerevisiae cell cycle. Cell 62: 213-224.

Li, Y., R. D. Moir, I. K. Sethy-Coraci, J. R. Warner and I. M. Willis, 2000 Repression of ribosome and tRNA synthesis in secretiondefective cells is signaled by a novel branch of the cell integrity pathway. Mol. Cell. Biol. 20: 3843-3851.

Lipowsky, G., F. R. Bischoff, P. Schwarzmaier, R. Kraft, S. Kostka et al., 2000 Exportin 4: a mediator of a novel nuclear export pathway in higher eukaryotes. EMBO J. 19: 4362-4371.

Liu, Y. P., M. NemerofF, Y. P. YAN and K. Y. Chen, 1997 Interaction of eukaryotic initiation factor $5 \mathrm{~A}$ with the human immunodeficiency virus type $1 \mathrm{Rev}$ response element RNA and U6 snRNA requires deoxyhypusine or hypusine modification. Biol. Signals 6: 166174.

Madden, K., Y. J. Sheu, K. Baetz, B. Andrews and M. Snyder, 1997 SBF cell cycle regulator as a target of the yeast PKC-MAP kinase pathway. Science 275: 1781-1784.

Mangus, D. A., N. Amrani and A. Jacobson, 1998 Pbplp, a factor interacting with Saccharomyces cerevisiae poly(A)-binding protein, regulates polyadenylation. Mol. Cell. Biol. 18: 7383-7396.

McBride, A. E., V. H. Weiss, H. K. Kim, J. M. Hogle and P. A. Silver, 2000 Analysis of the yeast arginine methyltransferase Hmtlp/ Rmtlp and its in vivo function. Cofactor binding and substrate interactions. J. Biol. Chem. 275: 3128-3136.

Minvielle-Sebastia, L., P. J. Preker, T. Wiederkehr, Y. Strahm and W. Keller, 1997 The major yeast poly(A)-binding protein is associated with cleavage factor IA and functions in premessenger RNA 3'-end formation. Proc. Natl. Acad. Sci. USA 94: 78977902.

Munroe, D., and A. Jacobson, 1990 mRNA poly(A) tail, a 3' enhancer of translational initiation. Mol. Cell. Biol. 10: 3441-3455.

Nierras, C. R., and J. R. Warner, 1999 Protein kinase C enables the regulatory circuit that connects membrane synthesis to ribosome synthesis in Saccharomyces cerevisiae. J. Biol. Chem. 274: 1323513241.

Oliveira, C. C., and J. E. McCarthy, 1995 The relationship between eukaryotic translation and mRNA stability. A short upstream open reading frame strongly inhibits translational initiation and greatly accelerates mRNA degradation in the yeast Saccharomyces cerevisiae. J. Biol. Chem. 270: 8936-8943.

Paravicini, G., M. Cooper, L. Friedli, D. J. Smith, J. L. Carpentier et al., 1992 The osmotic integrity of the yeast cell requires a functional PKC1 gene product. Mol. Cell. Biol. 12: 4896-4905.

PARK, M. H., E. C. WolfF and J. E. Folk, 1993 Hypusine: its posttranslational formation in eukaryotic initiation factor $5 \mathrm{~A}$ and its potential role in cellular regulation. Biofactors 4: 95-104.

Park, M. H., E. C. WolfF, Y. B. LeE and J. E. Folk, 1994 Antiproliferative effects of inhibitors of deoxyhypusine synthase. Inhibition of growth of Chinese hamster ovary cells by guanyl diamines. J. Biol. Chem. 269: 27827-27832.

Park, M. H., Y. B. LeE and Y. A. Joe, 1997 Hypusine is essential for eukaryotic cell proliferation. Biol. Signals 6: 115-123.

Park, M. H., Y. A. JoE and K. R. KANG, 1998 Deoxyhypusine synthase activity is essential for cell viability in the yeast Saccharomyces cerevisiae. J. Biol. Chem. 273: 1677-1683.

Peat, T. S., J. Newman, G. S. Waldo, J. Berendzen and T. C. TerwilLIGER, 1998 Structure of translation initiation factor 5A from Pyrobaculum aerophilum at $1.75 \AA$ resolution. Structure 6: 1207 1214.

Posas, F., M. Takekawa and H. Saito, 1998 Signal transduction by MAP kinases in budding yeast. Curr. Opin. Microbiol. 1: 175-182.

Rose, M. D., F. Winston and P. Hieter, 1990 Methods in Yeast Genetics: A Laboratory Course Manual. Cold Spring Harbor Laboratory Press, Cold Spring Harbor, NY.

Ruhl, M., M. Himmelspach, G. M. Bahr, F. Hammerschmid, H. JAKSCHE et al., 1993 Eukaryotic initiation factor 5A is a cellular target of the human immunodeficiency virus type 1 Rev activation domain mediating trans-activation. J. Cell Biol. 123: 1309-1320.

SAchs, A. B., and R. W. DAvis, 1989 The poly(A) binding protein is required for poly(A) shortening and $60 \mathrm{~S}$ ribosomal subunitdependent translation initiation. Cell 58: 857-867.

SAchs, A. B., and R. W. DAvis, 1990 Translation initiation and ribosomal biogenesis: involvement of a putative rRNA helicase and RPL46. Science 247: 1077-1079.

Sadler, I., A. Chiang, T. Kurihara, J. Rothblatt, J. Way et al., 1989 A yeast gene important for protein assembly into the endoplasmic 
reticulum and the nucleus has homology to DnaJ, an Escherichia coli heat shock protein. J. Cell Biol. 109: 2665-2675.

Sasaki, K., M. R. Abid and M. Miyazaki, 1996 Deoxyhypusine synthase gene is essential for cell viability in the yeast Saccharomyces cerevisiae. FEBS Lett. 384: 151-154.

Schatz, O., M. Oft, C. Dascher, M. Schebesta, O. Rosorius et al., 1998 Interaction of the HIV-1 Rev cofactor eukaryotic initiation factor 5A with ribosomal protein L5. Proc. Natl. Acad. Sci. USA 95: $1607-1612$.

Schnier, J., H. G. Schwelberger, Z. Smit-McBride, H. A. Kang and J. W. Hershey, 1991 Translation initiation factor 5A and its hypusine modification are essential for cell viability in the yeast Saccharomyces cerevisiae. Mol. Cell. Biol. 11: 3105-3114.

Schwartz, D. C., and R. Parker, 1999 Mutations in translation initiation factors lead to increased rates of deadenylation and decapping of mRNAs in Saccharomyces cerevisiae. Mol. Cell. Biol. 19: 5247-5256.

Shi, X. P., K. C. Yin, J. Ahern, L. J. Davis, A. M. Stern et al., 1996a Effects of N1-guanyl-1,7-diaminoheptane, an inhibitor of deoxyhypusine synthase, on the growth of tumorigenic cell lines in culture. Biochim. Biophys. Acta 1310: 119-126.

Shi, X. P., K. C. Yin, Z. A. Zimolo, A. M. Stern and L. Waxman, 1996b The subcellular distribution of eukaryotic translation initiation factor, eIF-5A, in cultured cells. Exp. Cell Res. 225: 348356.

Shi, X. P., K. C. YIN and L. Waxman, 1997 Effects of inhibitors of RNA and protein synthesis on the subcellular distribution of the eukaryotic translation initiation factor, eIF-5A, and the HIV-1 Rev protein. Biol. Signals 6: 143-149.

Sikorski, R. S., and P. Hieter, 1989 A system of shuttle vectors and yeast host strains designed for efficient manipulation of DNA in Saccharomyces cerevisiae. Genetics 122: 19-27.

Stade, K., C. S. Ford, C. Guthrie and K. Weis, 1997 Exportin 1 (Crm1p) is an essential nuclear export factor. Cell 90: 1041-1050.
Stage-Zimmermann, T., U. Schmidt and P. A. Silver, 2000 Factors affecting nuclear export of the $60 \mathrm{~S}$ ribosomal subunit in vivo. Mol. Biol. Cell 11: 3777-3789.

Struhl, K., D. T. Stinchcomb, S. Scherer and R. W. Davis, 1979 High-frequency transformation of yeast: autonomous replication of hybrid DNA molecules. Proc. Natl. Acad. Sci. USA 76: 10351039.

Tarun, S. Z., Jr., S. E. Wells, J. A. Deardorff and A. B. Sachs, 1997 Translation initiation factor eIF4G mediates in vitro poly(A) taildependent translation. Proc. Natl. Acad. Sci. USA 94: 9046-9051.

Taura, T., H. Krebber and P. A. Silver, 1998 A member of the Ran-binding protein family, Yrb2p, is involved in nuclear protein export. Proc. Natl. Acad. Sci. USA 95: 7427-7432.

Verna, J., A. Lodder, K. Lee, A. Vagts and R. Ballester, 1997 A family of genes required for maintenance of cell wall integrity and for the stress response in Saccharomyces cerevisiae. Proc. Natl. Acad. Sci. USA 94: 13804-13809.

Watanabe, M., C. Y. Chen and D. E. Levin, 1994 Saccharomyces cerevisiae PKC1 encodes a protein kinase C (PKC) homolog with a substrate specificity similar to that of mammalian PKC. J. Biol. Chem. 269: 16829-16836.

Wohl, T., H. Klier, H. Ammer, F. Lottspeich and V. Magdolen, 1993 The HYP2 gene of Saccharomyces cerevisiae is essential for aerobic growth: characterization of different isoforms of the hypusine-containing protein Hyp2p and analysis of gene disruption mutants. Mol. Gen. Genet. 241: 305-311.

Xu, A., and K. Y. Chen, 2001 Hypusine is required for a sequencespecific interaction of eukaryotic initiation factor $5 \mathrm{~A}$ with postSELEX RNA. J. Biol. Chem. 276: 2555-2561.

ZuK, D., and A. JACOBson, 1998 A single amino acid substitution in yeast eIF-5A results in mRNA stabilization. EMBO J. 17: 29142925.

Communicating editor: L. Pillus 